\title{
DATA BASE DEVELOPMENT AND EVALUATION OF EARTHQUAKE DAMAGE REPORTS UNDER THE SEISIMPACT-THES SYSTEM
}

Savvaidis P. ${ }^{1}$, Doukas I. ${ }^{1}$, Hatzigogos Th. ${ }^{2}$, Tziavos I.N. ${ }^{3}$, Kiratzi A. ${ }^{4}$, Roumelioti Z. ${ }^{4}$, Savvaidis A. , Theodulidis N. ${ }^{5}$, Drakatos 'G. ${ }^{6}$, Koutoupes S.', Karantonis $G^{8}{ }^{8}$ and Sotiriadis $A^{8}$

${ }^{1}$ Laboratory of Geodesy, Division of Geotechnical Engineering, Department of Civil Engineering, Aristotle University of Thessaloniki, psav@civil.auth.gr, jdoukas@civil.auth.gr

${ }^{2}$ Laboratory of Soil Mechanics and Foundations, Division of Geotechnical Engineering, Aristotle University of Thessaloniki, hatz@geo.civil.auth.gr

${ }^{3}$ Division of Geodesy and Surveying, Department of Rural and Surveying Engineering, Aristotle University of Thessaloniki, tziavos@eng.auth.gr

${ }^{4}$ Department of Geophysics, Aristotle University of Thessaloniki, P.O. Box 352-1, 54124, Thessaloniki,kiratzi@geo.auth.gr,zroum@lemnos.geo.auth.gr

${ }^{5}$ Institute of Engineering Seismology and Earthquake Engineering, P.O. Box 53, 55102, alekos@itsak.gr,ntheo@itsak.gr

${ }^{6}$ National Observatory of Athens, Institute of Geodynamics, P.O. Box 20048, 11810, Athens, g.drakat@egelados.gein.noa.gr

${ }^{7}$ Hellas On Line (HOL), 59-61 Agiou Konstantinou str, Building B, 15124 Marousi, Athens, skout@hol.net

${ }^{8}$ Agiltech S.A., 18 Aetideon, 15561, Holargos, Athens, gkarant@agiltech.gr, asot@agiltech.gr

\section{ABSTRACT}

One of the scopes of the SEISIMPACT-THES project is to organize into digital form and evaluate the records of reported damage, related to the occurrence of the 1978 Thessaloniki earthquake $(M w=6.5)$. For the exploitation of these data, an advanced Information System is under development that will include:

- A properly designed database

- A Geographic Information System containing all the necessary data (after digitization and corrections) enriched with more recent data, as well as topographic, geological and geophysical data of the region (metropolitan area of Thessaloniki)

- A model system of accessing the above via the web and mobile devices

The basic data for the implementation of the project are derived from the archives of the Agency for the Relief of Seismic Catastrophes in Northern Greece (YASBE). The data are included in the forms of inspection of buildings carried out in Thessaloniki shortly afterwards the 1978 earthquake. It is estimated that there are roughly 63,000 building inspection forms in the region of Thessaloniki.

The exploitation of this rich database with the description on the damage that the buildings suffered will result in a complete electronic database properly standardized so that it can be linked to the geographic data of a Geographic Information System. The database structure will allow multiple queries and processes to study in depth the behavior of buildings in Thessaloniki, and its correlation with other geological, geophysical, geotechnical factors. 


\section{INTRODUCTION}

The development of databases containing information of the buildings that suffered damage due to earthquakes constitutes a methodology that is used with increasing frequency during the last few years. The information included in these databases basically concerns the type of damage recorded for each building and is connected to their structural characteristics. At the same time, a large quantity of related information (e.g. spatial, geographical, economical, demographical etc.) is recorded. All these data can be utilized by many categories of potential users, such as scientists, engineers, professionals, public employees, but also institutions of the private as well as the public sector.

Geographical Information Systems (GIS) are the main tool to manage data stored in the above mentioned databases. In some cases, new software packages based on the Expert Systems technology have been developed for the management, modification or extension of these data. All efforts contribute to the creation of a framework of procedures aiming to solve problems created after serious seismic incidents to the population, as well as in studies and the development of action plans and strategies for the relief of population and the effective confrontation of similar natural phenomena in the future. Usually, on the basis of seismic data analysis and the type of buildings, several scenarios are being studied about the ways earthquakes affect the urban environment. The development of such simulation models - but also forecast models for the estimation of emergency situations and their satisfactory confrontation - is associated with the type of structures and their quality in the particular geographical area under investigation. Therefore, it is obvious that the models developed with the help of GIS spatial analysis tools may assist the authorities in decisionmaking for emergency management, a task with direct social and economic impact.

Different techniques and systems have been used to record and manage damage information about buildings. Among them:

- The Federal Emergency Management Agency (FEMA) and the Defense Threat Reduction Agency (DTRA) in U.S.A. have developed the "Consequences Assessment Tool Set" (CATS), a software tool aiming at an improved planning of measures of confrontation of natural or anthropogenic emergencies of various forms, among which of course are the earthquakes (Swiatek \& Kaul 1998). With respect to earthquakes, CATS deals with the damage in buildings, infrastructure and the probability of existence of victims.

- The Federal Emergency Management Agency (FEMA) and the National Earthquake Hazards Reduction Program (NEHRP) in U.S.A. have developed the HAZUS (HAZards United States) system for the reduction of seismic danger in the country. This particular system has been developed so that it can be used by state institutions, at local and national level, to estimate seismic risk, more effective seismic-resistant planning and the organization of practical measures of confrontation of seismic destructions (Bouhafs et al., 1998). It also uses mathematic relations and information with regard to the epicenter and the size of likely future earthquakes, the vulnerability of existing building infrastructure, the local geology, as well as demographic elements, aiming to the calculation of the impact of future earthquakes (Bausch et al., 1999).

- A system based on the technology of GIS and ArcView software contains a database of expected ground movements during various scenarios of earthquakes in correlation to already observed damage data from more than 62,000 buildings in the region of Los Angeles (O' Rourke et al., 2000).

- The Extremum system has been developed by the Russian State Federal System of Seismological Observations and Earthquake Prediction (FSSN) and EMERCOM. It can manage and analyze spatial and descriptive data that include seismic risk and the estimate of the vulnerability of structures (Milutinovic 2000).

- Another system based on the technology of GIS has been developed by the Institute of Architecture and City Planning in Japan. The system contains a digital map of the city of Nishinomiya showing the location of buildings and a database with damage data after an earthquake that occurred in 1995 (Murao and Yamazaki 1999, Umemura et al., 2002). 
Greece has suffered many times from strong earthquakes that caused human casualties as well as considerable damage to public and private infrastructure. The 1978 earthquake in Thessaloniki $(M w=6.5)$ enhanced the beginning of a more systematic confrontation of the impact of such phenomena. This happened because it was the first time that a powerful earthquake affected a big modern city of roughly one million of residents. Thessaloniki presented the formal characteristics of Greek urban built environment: buildings with 4 to 8 storey, large population in numbers and density, mixed land use, traffic problems and lack of effective planning to manage natural catastrophes.

The SEISIMPACT-THES System organizes into digital form and evaluates the records of reported damage in buildings connected to the occurrence of the 1978 Thessaloniki earthquake. An an advanced Information System has been developed that includes a properly designed database, a Geographic Information System containing the necessary data (after digitization and corrections) enriched with more recent data, as well as topographic, geological and geophysical data of the region (metropolitan area of Thessaloniki). It includes also a model system of accessing the above via the web and mobile devices (for details see Koutoupes et al. 2004).

The participants collaborating in the completion of the project are:

- The Laboratory of Geodesy, Division of Geotechnical Engineering of the Department of Civil Engineering, Aristotle University of Thessaloniki.

- The Department of Geodesy and Surveying, Aristotle University of Thessaloniki.

- The Department of Geophysics, Aristotle University of Thessaloniki.

- The Institute of Engineering Seismology \& Earthquake Engineering (ITSAK).

- Hellas On Line (HOL) S.A., a private company working with Internet Information Services.

- AgilTech S.A. (subcontractor of HOL S.A.) for software systems design and development.

The above participants have also valued from the cooperation with engineers employed by The Agency for the Relief of Seismic Catastrophes in Northern Greece (YASBE), which provided the core data, as the basic data for the project implementation. As already mentioned, the data are included in the forms of inspection of buildings carried out in Thessaloniki shortly after the 1978 earthquake. It is estimated that there are roughly 63,000 building inspection forms in the region of Thessaloniki.

\section{INSPECTION FORMS FOR EARTHQUAKE DAMAGED BUILDINGS AND THE SEISIMPACT-THES DATABASE}

One of the fundamental duties of emergency management agencies is the inspection of public and private structures and buildings after a strong earthquake. In this way, safe use of buildings can be ensured and damage can be recorded for scientific and statistical evaluation. This procedure has been followed in all major earthquakes in Greece, starting from Thessaloniki in 1978 up to the most recent strong earthquake of Athens in 1999, but also in moderate earthquakes (Dandoulaki et al. 1998).

This subject is of high importance since, inspection after the earthquake helps in reducing the probability of casualties from aftershocks, a fact that gives the character of urgent and imposes the need for quick actions. The evaluation of the condition of buildings will then give the likely number of citizens that should be accommodated in settlements and will appease the other citizens as far as their residences. On the other hand, the inspections must record in an equitable way the observed damage so that they can be used for statistical and mainly for scientific reasons.

After the Thessaloniki earthquake, a situation of chaos was created due to the panic, the destructions, the lack of information and the innumerable calls on help, but also on control of static condition and damage of buildings (fig.1). By that time, there was no specific procedure for the inspection of buildings and infrastructure. However, after this first period the state agencies reacted. Forms were drafted, printed and distributed during the first days after the earthquake. The buildings were inspected by two member teams of engineers to be classified in three categories with respect 
to their damage and usability (Green: Usable - no serious damage, Yellow: Temporarily unusable - with damage, usable after the repairs, Red: Unusable, dangerous) (fig.2).

The result of this procedure was the creation of an enormous database from the inspection forms that contained classification of buildings, but also certain additional information on types of damage, structure and size of building, etc. After the completion of the inspections (approximately two months for the first and second degree inspection), roughly 63000 buildings in the region of Thessaloniki were inspected (corresponding to roughly 250000 apartments, offices and shops). All data were kept in the archives of the newly established Agency for the Relief of Seismic Catastrophes in Northern Greece. Table 1 shows an overview of the number of inspections and the results (Doukas 2003).

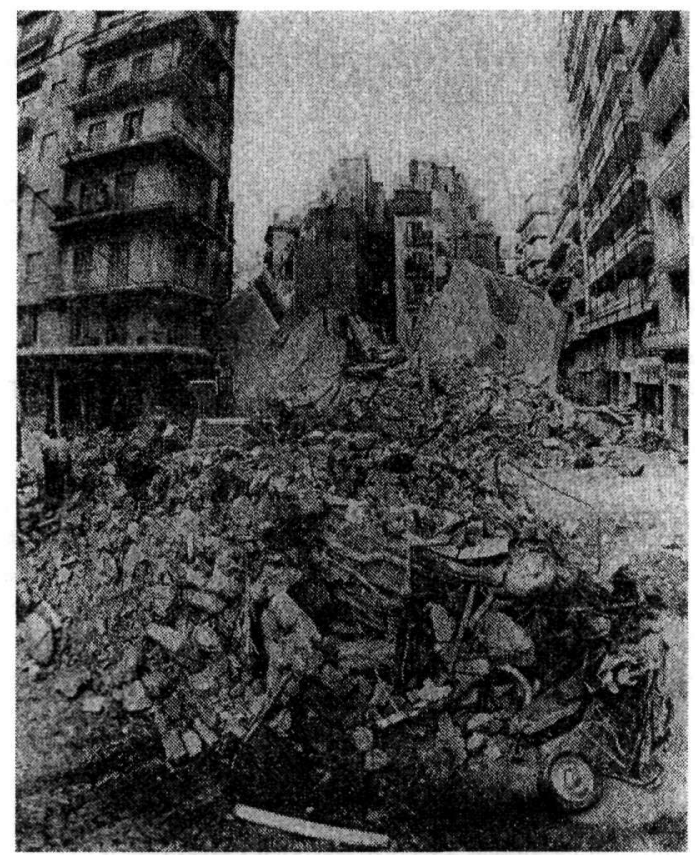

Figure 1. Building collapse in Thessaloniki after the 1978 earthquake
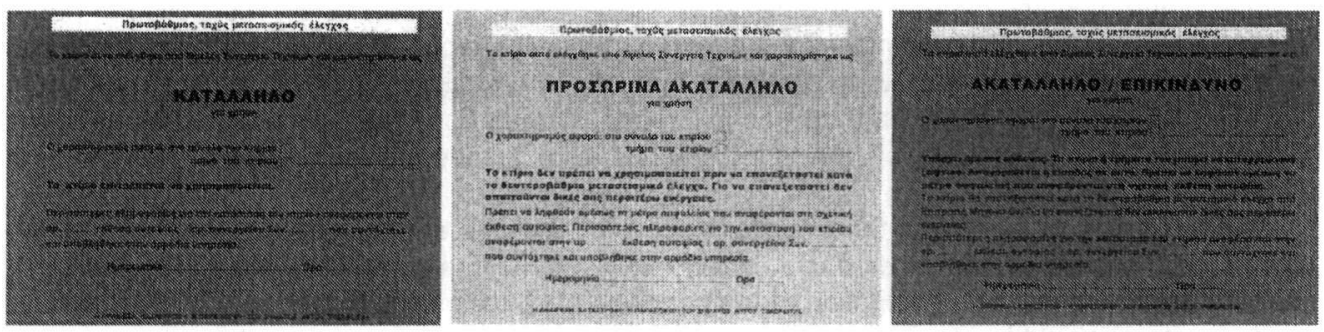

Figure 2. Post-earthquake building safety classification (Green: Usable - Yellow: Temporarily unusable - Red: Unusable, dangerous)

The data of the inspection forms of the Thessaloniki 1978 earthquake have been used to some extent for scientific research in the past (Papacharisis 1980, Penelis et al., 1988).

In 1984, one year after the establishment of the Earthquake Planning and Protection Organization of Greece, the inspection form was re-designed to assist the standardized import of information, prevent errors and shorten the time needed to fill it in. These inspection forms were used after a number of devastating earthquakes in Greece undergoing revisions, improvements and additions. 


\begin{tabular}{lcc}
\hline $\begin{array}{l}\text { Post-earthquake building safety clas- } \\
\text { sification in the area of } \\
\text { Thessaloniki }\end{array}$ & Number of buildings & $\begin{array}{l}\text { Number of apartments, } \\
\text { shops, offices }\end{array}$ \\
\hline $\begin{array}{l}\text { GREEN } \\
\text { (Usable - no serious damage) }\end{array}$ & 46441 & 184082 \\
\hline $\begin{array}{l}\text { YELLOW } \\
\text { (Temporarily unusable - with } \\
\text { damage, usable after the repairs) }\end{array}$ & 12823 & 61270 \\
\hline $\begin{array}{l}\text { RED } \\
\text { (Unusable, dangerous) }\end{array}$ & 3648 & 4648 \\
\hline TOTAL & 62912 & 250000 \\
\hline
\end{tabular}

The structure of the main database of the SEISIMPACT-THES project was based on the design of three paper inspection forms used for post- or pre-seismic control of buildings:

- Inspection forms used after the Thessaloniki 1978 earthquake, being the main source of information.

- Inspection forms used after the Athens 1999 earthquake.

- Forms for pre-seismic control of buildings according to a proposal by the Earthquake Planning and Protection Organization of Greece (Karabinis et al., 2002).

The design of the SEISIMPACT-THES database was flexible enough to allow the input of inspection data from existing files related to a past earthquake incident in Greece along with the Thessaloniki data. It can also be used and store data from pre-seismic inspections of buildings. User-friendly entry tools in Microsoft Excel and Microsoft Access have been developed for the quick and reliable input of inspection details in the database (fig. 3).

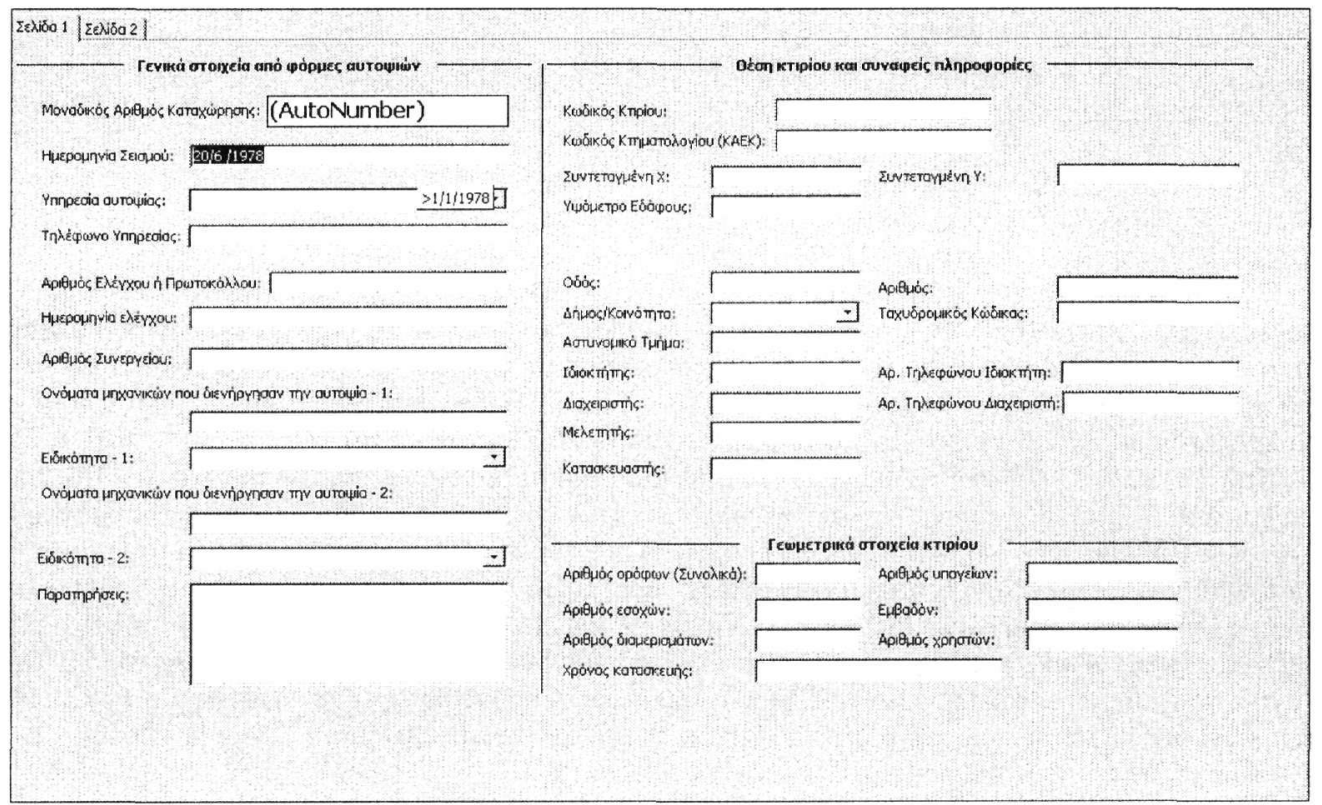

Figure 3. An example of a page of the Microsoft Access entry tool (in Greek)

The fields of the SEISIMPACT-THES database concerning the observed damage of a particular building, are organized in the following groups, as presented in Table 2:

- Location (address: street name and number) of building and relevant information

- Geometric characteristics of the building

- Main use of building 
- Structural type

- Inspection results - damage

- Estimation of Structural Capacity

- Capacity Curve - Vulnerability Curve

- Cost of repair

- Characterization of soil properties

Table 2. Structure of the SEISIMPACT-THES main database

\begin{tabular}{|c|c|c|}
\hline Field code & Description & Input \\
\hline \multirow{4}{*}{ A5.1 } & \multirow{4}{*}{ Safety classification of building } & $\mathrm{K} 1=\mathrm{Green}$ \\
\hline & & $\mathrm{K} 2=$ Yellow \\
\hline & & $\mathrm{K} 3=\mathrm{Red}$ \\
\hline & & K4=Collapsed \\
\hline A5.1a & Valid only for part of building & $\mathrm{K} 1=\mathrm{Yes}, \mathrm{K} 2=\mathrm{No}$ \\
\hline $\mathrm{A} 5.2 \mathrm{a}$ & Damage to plaster & $\mathrm{K} 1=\mathrm{Yes}, \mathrm{K} 2=\mathrm{No}$ \\
\hline $\mathrm{A} 5.2 \mathrm{~b}$ & Damage to brickwork & $\mathrm{K} 1=\mathrm{Yes}, \mathrm{K} 2=\mathrm{No}$ \\
\hline A5.2c & Damage to slates & $\mathrm{K} 1=\mathrm{Yes}, \mathrm{K} 2=\mathrm{No}$ \\
\hline A5.2d & Damage to beams & $\mathrm{K} 1=\mathrm{Yes}, \mathrm{K} 2=\mathrm{No}$ \\
\hline $\mathrm{A} 5.2 \mathrm{e}$ & Damage to pillars & $\mathrm{K} 1=\mathrm{Yes}, \mathrm{K} 2=\mathrm{No}$ \\
\hline A5.2f & Damage to concrete walls & $\mathrm{K} 1=\mathrm{Yes}, \mathrm{K} 2=\mathrm{No}$ \\
\hline A5.2h & Damage to roof & $\mathrm{K} 1=\mathrm{Yes}, \mathrm{K} 2=\mathrm{No}$ \\
\hline A5.3 & Number of unusable households & \\
\hline A5.4 & $\begin{array}{l}\text { Access to certain parts of building de- } \\
\text { nied }\end{array}$ & $\mathrm{K} 1=\mathrm{Yes}, \mathrm{K} 2=\mathrm{No}$ \\
\hline A5.5. & Disconnection of facility networks & $\begin{array}{l}\mathrm{K} 1=\text { Electricity, } \mathrm{K} 2=\text { Water, } \\
\mathrm{K} 3=\text { Gas }\end{array}$ \\
\hline A5.6 & Is propping necessary? & $\mathrm{K} 1=\mathrm{Yes}, \mathrm{K} 2=\mathrm{No}$ \\
\hline A5.7 & $\begin{array}{l}\text { Elements that must be urgently pulled } \\
\text { down }\end{array}$ & Short description \\
\hline
\end{tabular}

\section{THE SEISIMPACT-THES GEOGRAPHIC INFORMATION SYSTEM}

On the basis of the above-mentioned information, a Geographic Information System is being developed using ESRI's ArcGIS and ArcIMS software. The ultimate purpose is to provide support for making decisions based on spatial and descriptive data. GIS will be also invaluable for collecting, maintaining and using geographic information, as well as for producing both standardized and customized cartographic products (Savvaidis and Ifadis 2000).

The SEISIMPACT-THES GIS system is based on a detailed digital map of the greater Thessaloniki area. The map displays city blocks and roads as well as different municipality boundaries. Addresses of buildings whose damage has been stored in the database described in the previous paragraph are being linked to their geographical location on the map through an address-matching procedure (fig. 4). Additional layers of information include seismological and geotechnical data, such as historical and instrumental seismicity, maximum values of peak ground acceleration (PGA map) using empirical relations, values of maximum spectral acceleration in discrete periods (PSA map) depending on the target scenario earthquakes considered, tectonic lines, site effects - expressed as mean values of shear - wave velocity if available.

Spatial analysis based on the combined use of geographic and descriptive data may result in_an evaluation of the reliability of the buildings. Spatial queries will involve several types of questions:

- Safety classification (red - yellow - green) of a specific building (or buildings in a region)

- Damage a specific building had suffered (or buildings in a region)

- Locations (buildings) at which a specific type of damage had occurred. 
The application is intended to be accessible by authorized users over the Internet, instantly providing information about recorded damage as well as related geographical information. The GIS user would point with the cursor to a location on the map displayed or type-in the address of a building, and retrieve information about the damage or other characteristics of the selected data layers related to that location. Furthermore the user will have the ability to find locations that meet certain criteria, such as "close to a road", "on a specified geologic formation or soil type", "more than one type of damage", among others. The selected locations can either be highlighted on screen, or shown on a new view. On both cases, interactive visualization will play an important role.

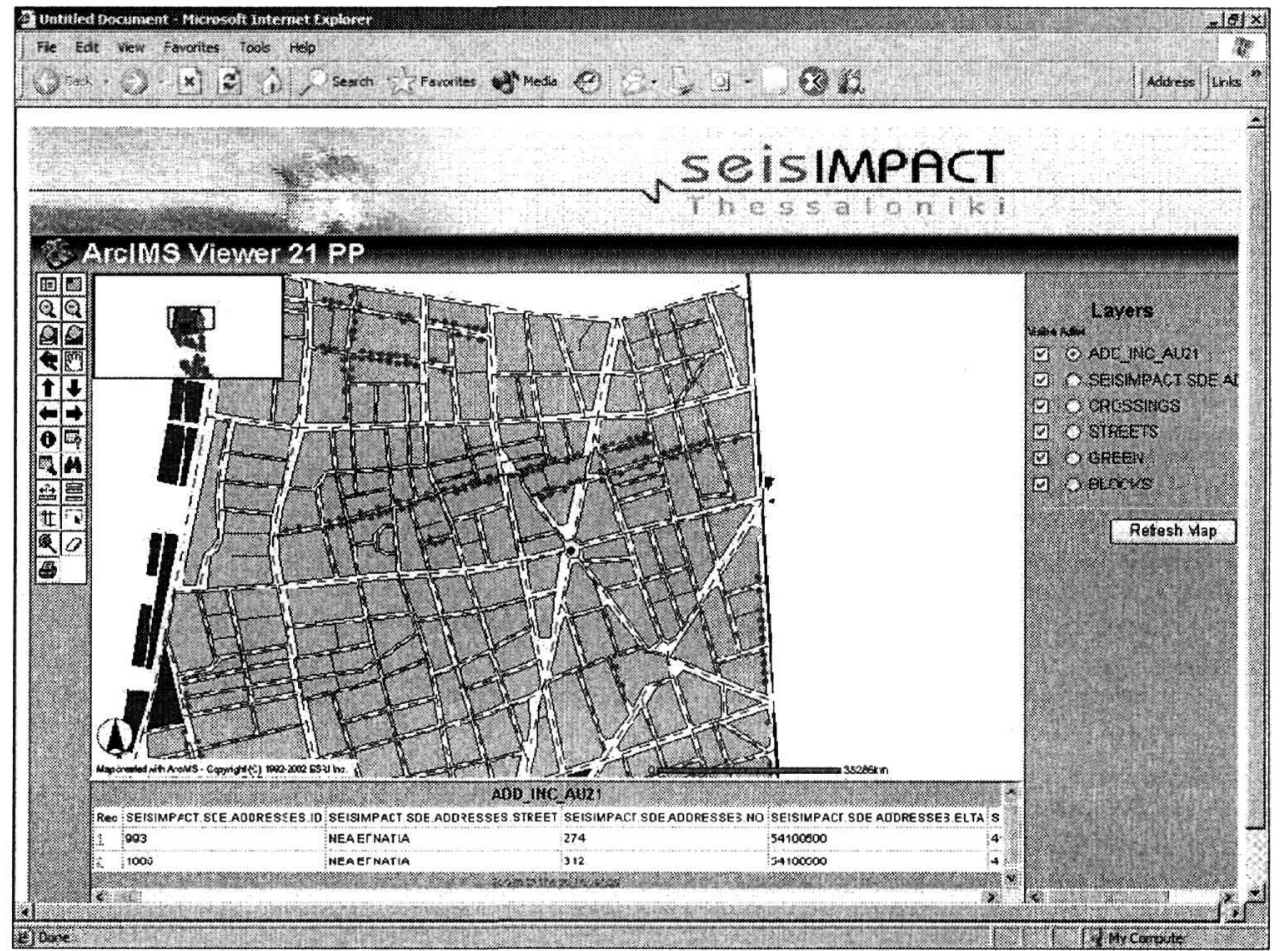

Figure 3. An example of the address-matching procedure using ArcGIS tools

Additionally, the stored data and the spatial analysis results will be employed for a better understanding of the role of site effects in the amplification of the ground motion and studying of nonlinear phenomena. A microtremors study in the city of Thessaloniki has been already conducted as well as geophysical measurements in specific sites for which geotechnical data were not available. A rich databank of waveforms from the weak and strong motion from earthquakes that occurred in the broader area has already been available to the SEISIMPACT-THES research group. These data come from the accelerograph network and the telemetry seismological network operated by two of the participants. All these data will be put together to give the opportunity to do a detailed study of site effects, to test synthetic models against the original observations, and refine their parameters. Thus, amplification - reduction curves can be estimated for practical engineering analysis.

A major benefit of the system is related to the simulation of strong ground motion from postulated events. In this approach we see what the past can teach us about the future by simulating the expected ground motions from a number of possible scenarios of earthquake occurrence from the rupture of nearby faults. The urban area of Thessaloniki is affected by a number of seismic sources that fall into three categories in terms of their distance from the city. The first category of earthqyake sources is very close to the city, the second category of sources is in intermediate distances and the third category of seismic sources are far away from the city. It is evident that the seismic waves 
produced by these sources will have spectra at different frequencies. Low frequencies are expected from the more distant sources for instance. The built environment of the city will not respond in the same manner to the postulated ruptures from these sources. It is one of our main tasks to predict the distribution of strong ground motions from these postulated events and hence evaluate the distribution of damage (intensities) within the city.

Thessaloniki is not vulnerable to an earthquake which will have the same focus as the 1978 one in the sense that the return period of the rupture from the same fault is large. But the city is vulnerable from the rupture of other faults that are clearly observed on the geological maps, seen in the topography, in satellite photographs, and detected from offshore geophysical prospecting. To estimate the parameters of the expected ground motion in terms of acceleration, velocity and displacement, the good knowledge of the focal mechanism of the expected events, their parameters, and the previous experience collected over the years will be utilized (Benetatos and Kiratzi, 2004; Roumelioti et al., 2003a, b; 2004a, b). As a result of this approach, a clear view of the Fourier spectra of key parameters of strong ground motion from future modeled events near the metropolitan city of Thessaloniki will be identified. Therefore, when the epicenter of the earthquake is in the broader area of Thessaloniki there will be an immediate presentation of the predicted damage. Finally, a number of scenarios regarding earthquakes affecting the built environment of the Prefecture of Thessaloniki will be produced and tested on the basis of the information stored in the SEISIMPACT-THES database and GIS concerning the real damage the buildings had suffered in ThessaIoniki (Kiratzi et al., 2004).

\section{CONCLUSIONS}

The project implementation is expected to result in benefits for the state, the scientific institutions and the companies participating in the project as well as for citizens. The exploitation of the rich database with the description of damage of the 1978 earthquake will result to a complete electronic file of inspections properly standardized so that it can be linked to the geographic data of the Geographic Information System. The database structure will allow multiple queries and processes, to study in depth the behavior of buildings in Thessaloniki, and its correlation with other geological, geophysical, geotechnical factors.

The public organizations concerned with the relief of earthquake impact will have the possibility to retrieve important information regarding the static behavior of buildings as well as the expected damage according to several scenario earthquakes. A new market of services will be created with benefits for the while range of involved parties (Public Services, engineers, notaries, lawyers, seismologists, individuals).

The participating institutions can use the above-mentioned data for further research and contribute to knowledge regarding consequences of seismic phenomena to various sectors of the social, economical and technical activity.

Therefore, the benefits for the scientific community can be summarized to the following:

- A detailed evaluation of the observed damage in the buildings of Thessaloniki taking into account the spatial distribution of different types of damage with the help of the GIS system

- Improvement - Development of methodology for the effects of local conditions using microtremors

- Improvement - Development of methodology for determination of geophysical ground properties by deployment of special networks

- Comprehension of the consequences of various seismic scenarios to the built environment of Thessaloniki.

- Strong motion simulation in various locations of Thessaloniki from a future strong earthquake.

- Evaluation of the reliability of methodologies based on the earthquake of 1978 .

Benefits for companies are summarized as follows:

- Know-how increase through their collaboration with scientific institutions of the project on post-seismic inspection data management and generally issues of managing and processing geographically distributed information. 
- Gain important experience through the implementation of a complex information system that interconnects a specialized database, a GIS and a Web application.

- Ability of know-how development in mobile applications for mobile computers (PDAs) and in location-based applications.

- Opportunity for commercial exploitation of an innovative system, both by providing a service over Internet, and reselling a stand-alone application software package.

Finally, even individual citizens will be able to make very quick retrievals of specified information in many combinations and with different criteria, e.g. to easily locate areas with specific characteristics such as distribution / concentration of buildings characterized as green, yellow or red, buildings with particular damage (in relation to their spatial distribution, year built, number of floors) etc

\section{REFERENCES}

Bausch, D., Gath, T., Gonzalez, R., and Laton P., 1999. GIS-Based Hazard Mapping and Loss Estimation in the Safety Element of the General Plan for Riverside Co., California Cal. State University, Fullerton, Dept. of Geological Sciences.

Benetatos, Ch., and Kiratzi, A., 2004. Stochastic strong ground motion simulation of intermediate depth earthquakes: The cases of the 30 May 1990 Vrancea (Romania) and of the 22 January 2002 Karpathos island (Greece) events, Soil Dynamics and Earthquake Engineering, 24, 1-9.

Dandoulaki, M., Panoutsopoulou, M., loannides, K., 1998. An overview of post-earthquake building inspection practices in Greece and the introduction of a rapid building usability evaluation procedure after the 1996 Konitsa earthquake, In 11th European Conference on Earthquake Engineering, Balkema, Rotterdam.

Doukas, I., 2003. A Geographic Information System for the evaluation of damage of buildings after the 1978 Thessaloniki earthquake, Volume dedicated to the memory of Prof. Anthimos Bantelas, Laboratory of Geodesy, Department of Civil Engineering, University of Thessaloniki, 53-58.

Karabinis, A., Fotopoulos, M., and Avramopoulos, I., 2002. Application of pre-seismic inspection to constructions affected by earthquake, $2^{\text {nd }}$ Pan-Hellenic Congress in Earthquake Engineering and Engineering Seismology, Vol. 2, 43-52.

Kiratzi, A., Roumelioti, Z., Theodulidis, N., Benetatos, C., Savvaidis, A., Tziavos, I., Savvaidis, P., Hatzigogos, Th., Karantonis, G., and Koutoupes, S., 2004. SEISIMPACT-THES: Scenario earthquakes affecting the built environment of the Prefecture of Thessaloniki, presented In $10^{\text {th }}$ Congress of the Greek Society of Geology, Thessaloniki, paper included in the Bulletin of the Geol. Soc. of Greece, vol. XXXVI, 2004 (in press).

Koutoupes, S., Karantonis, G., Sotiriadis A., Kiratzi, A., Valadaki, K., Theodulidis N., Savvaidis, A., Tziavos, H., Savvaidis, P., and Doukas, I. 2004. SEISIMPACT-THES: Design, development and application of an Information System to assess the vulnerability to earthquake hazard of the built environment of the Prefecture of Thessaloniki, presented In $10^{\text {th }}$ Congress of the Greek Society of Geology, Thessaloniki, paper included in the Bulletin of the Geol. Soc. of Greece, vol. XXXVI, 2004 (in press).

Milutinovic, Z., 2000. Contribution to the Decision Making for Seismic Risk Management by Damage Assessment Models, Euro-Mediterranean Centre on Insular Coastal Dynamics, Malta.

Murao, O., and Yamazaki, F., 1999. Comparison of building damage evaluation by local governments after the 1995 Hyogoken-Nanbu Earthquake, Journal of Architecture, Planning and Environmental Engineering, No. $515,187-194$.

O' Rourke, T.D., Sang-Soo, J., R.T., Eguchi, and C. K., Huyck, 2000. Advanced GIS for Loss Estimation and Rapid Post-Earthquake Assessment of Building Damage", Multidisciplinary Center for Earthquake Engineering Research, University at Buffalo, State University of New York, Buffalo, New York.

Papacharisis, N., 1980. Ground properties in the area of Thessaloniki - A correlation to damage observed after the 1978 earthquake, Scientific papers of the Laboratory of Soil Mechanics and Foundations, Department of Civil Engineering, University of Thessaloniki, No. 6, 82-117.

Penelis, G., Sarigiannis D., Stavrakakis E., Stylianidis K., 1988. A statistical evaluation of damage to buildings in the Thessaloniki, Greece earthquake of June 20,1978, $9^{\text {th }}$ World Conference on Earthquake Engineering, Kyoto-Tokyo, Vol. VII, pp. 187-192, 1988.

Roumelioti, Z., Kiratzi, A., Theodoulidis, N., Kalogeras, I., and Stavrakakis, G., 2003a. Source directivity during the September 7, 1999 (Mw 5.9) Athens (Greece) earthquake obtained from strong-motion records, Pure and Applied Geophysics, 160 (12), $2301-2318$.

Roumelioti, Z., Kiratzi, A., and Melis, N., 2003b. Relocation of the July 26, 2001 Skyros Island (Greece) Earthquake Sequence Using the Double-Difference Technique, Phys. of the Earth and Planet. Int., 138, 231-239.

Roumelioti, Z., Kiratzi, A., and Dreger, D., 2004a. The source process of the July 26, 2001 Skyros Island (Greece) earthquake, Geophysical Journal International, 156 (3), 541-548. 
Roumelioti, Z., Kiratzi, A., and Theodoulidis, N., 2004b. Stochastic Strong Ground Motion Simulation of the 7 September 1999 Athens (Greece) Earthquake, Bulletin of the Seismological Society of America, 94(3), 1036 $-1052$.

Savvaidis, P., and Ifadis, I., 2000. An introduction to the Geographical Information Systems. Post-graduate program in Environmental Engineering, Department of Civil Engineering A.U.Th., Thessaloniki.

Swiatek, J. A., and Kaul D. C., 1998. Crisis prediction disaster management, SAIC Science and Technology Trends.

Umemura, K., Murao O., and Yamazaki, F., 2002. Development of GIS-based building damage database for the 1995 Kobe earthquake, Proc. of the $21^{\text {st }}$ Asian Conference on Remote Sensing, Taiwan, Vol. I, 389-394. 